\title{
An unusual example of exercise-induced asthma
}

\author{
G. K. C R O M P T O N \\ From the Chest Unit, City Hospital, Edinburgh, and the Department of Respiratory Diseases, University of \\ Edinburgh
}

\begin{abstract}
A patient with exercise-induced asthma is described in whom the post-exercise fall in F.E.V.l was not prevented by the inhalation of isoprenaline immediately before exercise but was almost completely prevented by subcutaneous atropine given 40 minutes before exercise. A large fall in F.E.V.$_{1}$ similar to the fall after exercise occurred after carbon dioxide-induced hyperventilation and voluntary hyperventilation performed at rest. Only a slight fall in F.E.V..$_{1}$ occurred when atropine was given before voluntary hyperventilation was performed. It is postulated that the post-exercise fall in F.E.V. $\cdot_{1}$ in this patient is due to hyperventilation reflexly causing bronchial constriction.
\end{abstract}

It is now well documented that a fall in forced expiratory volume (F.E.V.1) may occur after exercise in some asthmatic patients (Jones, Buston, and Wharton, 1962 ; Jones, Wharton, and Buston, 1963 ; McNeill, Nairn, Millar, and Ingram, 1966). Jones et al. (1962) observed that the fall in F.E.V.1 after exercise in asthmatic children was minimized or abolished by preliminary inhalation of isoprenaline sulphate. McNeill et al. (1966) gave a variety of drugs to young adult subjects but found that only adrenaline prevented the post-exercise fall in F.E.V..$_{1}$ either completely or partially.

Voluntary hyperventilation has been found to cause a small but significant fall in F.E.V.$_{1}$ in asthmatic subjects (Hafez and Crompton, 1968), but McNeill et al. (1966) were unable to demonstrate any significant changes in F.E.V. ${ }_{1}$ after hyperventilation stimulated by breathing $7 \%$ carbon dioxide for 8 minutes.

This report concerns a patient with exerciseinduced asthma in whom the administration of isoprenaline sulphate before exercise did not prevent or minimize the post-exercise fall in F.E.V..$_{\cdot 1}$, and in whom hyperventilation stimulated by re-breathing carbon dioxide and voluntary over-breathing produced a fall in F.E.V.1 as profound as that induced by exercise. Moreover the fall in F.E.V..$_{1}$ following exercise and hyperventilation was prevented almost completely by the previous subcutaneous administration of $0.6 \mathrm{mg}$. atropine sulphate.

\section{CASE REPORT}

The patient was a 40-year-old obese woman who weighed $83 \mathrm{~kg}$. and was $5 \mathrm{ft}$. 3 in. $(1.6 \mathrm{~m}$.) tall. She gave a history of wheeze and breathlessness after exertion for five years. When examined at rest no abnormalities were detected except obesity, but following exercise she developed a typical asthmatic attack.

The F.E.V.1 was measured by a modified Gaensler spirometer (McKerrow, McDermott, and Gilson, 1960). The exercise level in all the F.E.V.1 studies was $327 \mathrm{~kg} / \mathrm{m} . / \mathrm{min}$. for three minutes. A short period of three minutes was chosen because this was found to produce a substantial post-exercise fall in F.E.V.1 and periods of exercise of more than three minutes' duration distressed the patient. In all the studies the initial F.E.V.1 was between 2,000 and 2,500 ml. The predicted normal F.E.V.1 for the patient was $>2,200 \mathrm{ml}$. (Needham, Rogan, and McDonald, 1954).

Figure 1 shows the results of exercise studies. The studies were performed on different days. Following exercise there was a profound fall in F.E.V.1; $2 \%$ isoprenaline sulphate solution (using a Wright nebulizer with an oxygen flow rate of 8 litres per minute for two minutes) was given because the patient was distressed by her wheeze. Dramatic improvement occurred within five minutes. Isoprenaline given five minutes before exercise did not prevent the postexercise fall in F.E.V.1, but improvement occurred when isoprenaline inhalation was repeated after the F.E.V.1 had fallen. Subcutaneous atropine sulphate, $0.6 \mathrm{mg}$, given 40 minutes before exercise almost completely prevented the post-exercise fall in F.E.V.1. The F.E.V.1 fell by only $400 \mathrm{ml}$. five minutes after exercise compared with falls of almost $2,000 \mathrm{ml}$. following exercise alone, and after exercise preceded by the inhalation of isoprenaline. A placebo injection of saline $\mathbf{4 0}$ minutes before exercise did not prevent a post-exercise fall in F.E.V.1.

Figure 2 shows the effect of carbon dioxide-induced hyperventilation and voluntary hyperventilation on the F.E.V.1. Rebreathing of carbon dioxide was achieved by allowing the patient to breathe into a 6-litre Palmer spirometer containing $5 \%$ carbon 


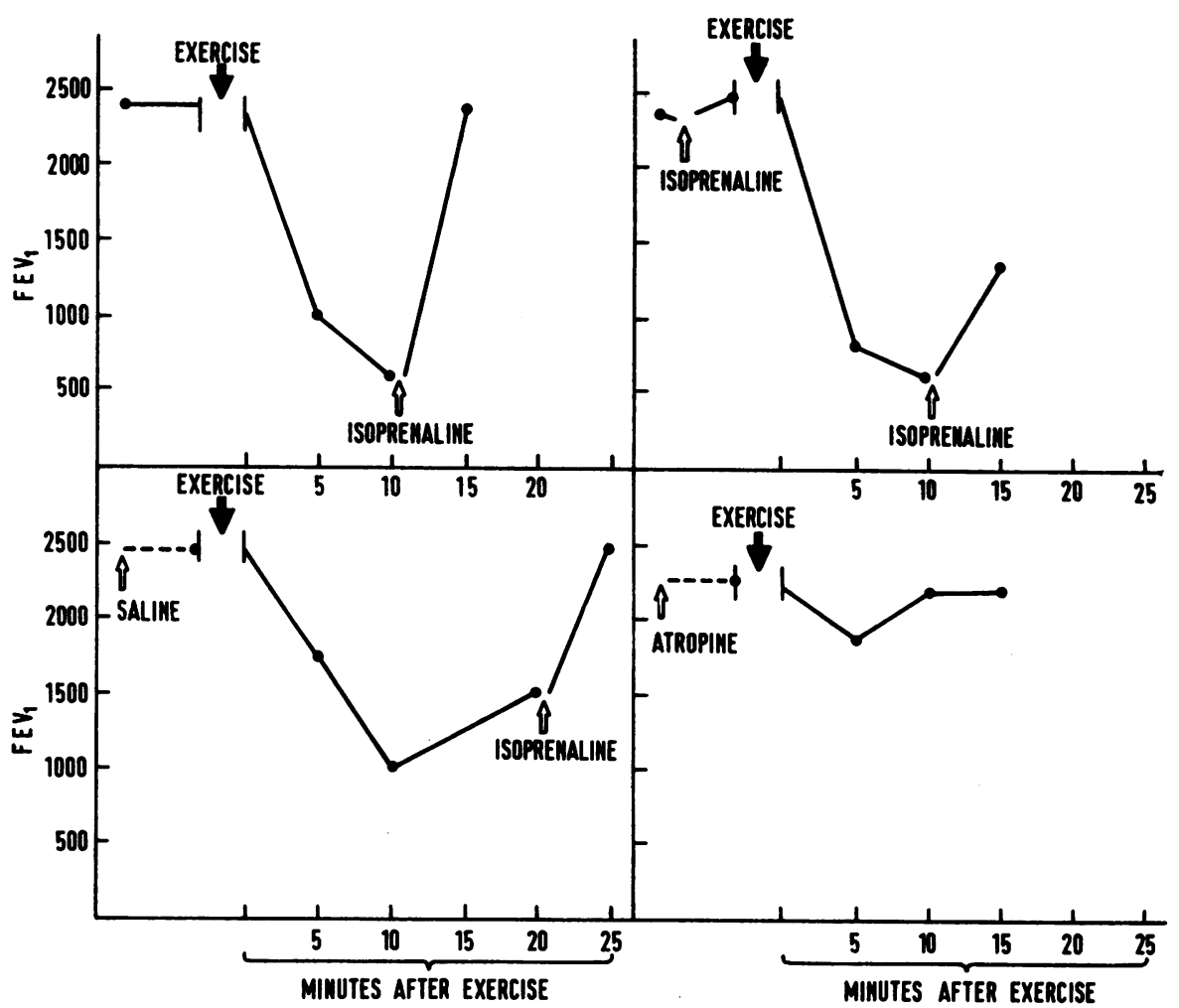

FIG. 1. The effect of exercise on the F.E.V..$_{1}$ (top left) exercise alone; (top right) isoprenaline inhalation before exercise; (bottom left) subcutaneous saline before exercise; (bottom right) subcutaneous atropine before exercise.

dioxide in oxygen for five minutes without a carbon dioxide absorber in the circuit. No attempt was made to measure the amount of carbon dioxide in the inspired air during the period of hyperventilation. Voluntary hyperventilation was achieved by encouraging the patient to over-breathe for three minutes into the spirometer with a carbon dioxide absorber in the circuit. The mean minute ventilation during the period of carbon dioxide-induced hyperventilation was 32.5 litres per minute, and during the period of voluntary over-breathing it was 46.2 litres per minute. Falls in F.E.V.1 similar to the falls observed after exercise occurred after carbon dioxide-induced hyperventilation and voluntary hyperventilation. When voluntary hyperventilation was performed 40 minutes after subcutaneous atropine only a slight fall in F.E.V.1 of 490 ml. was observed.

\section{DISCUSSION}

A profound fall in F.E..$_{\bullet_{1}}$ associated with distressing wheeze was observed in this patient following exercise. The post-exercise fall in F.E.V..$_{1}$ was not prevented or minimized by the administration of a sympathomimetic drug prior to exercise re- $\frac{-}{\sigma}$ ported in studies by Jones et al. (1962) and $\underline{3}$. McNeill et al. (1966). Isoprenaline did, however, 8 produce a dramatic improvement in F.E.V.$_{1}$ when $₹$ it was given by inhalation after the post-exercise $O$ fall in F.E.V..$_{1}$ had occurred.

McNeill et al. (1966) found that atropine $\operatorname{did}$ 을 not influence the post-exercise fall in F.E.V.1. N Nadel, Salem, Tamplin, and Tokiwa (1965), however, found that the increase in airway resistance $N$ produced by the inhalation of sulphur dioxide $\underset{\omega}{N}$ could be prevented by administering subcutaneous 0 atropine to healthy subjects before the inhalation ${ }_{0}$ of sulphur dioxide. It has also been shown that $\frac{D}{D}$ bronchoconstriction caused by the inhalation of $\stackrel{\oplus}{?}$ inert dusts can be prevented by atropine (Widdi- $\square$ combe, Kent, and Nadel, 1962; McDermott, $\stackrel{\circ}{\circ}$ 1962). It is possible that the post-exercise fall in F.E.V. $\cdot 1$ in some asthmatic patients is due to $\mathbb{\mathbb { Q }}$ hyperventilation reflexly causing the bronchi to constrict, and if this were the case one might 

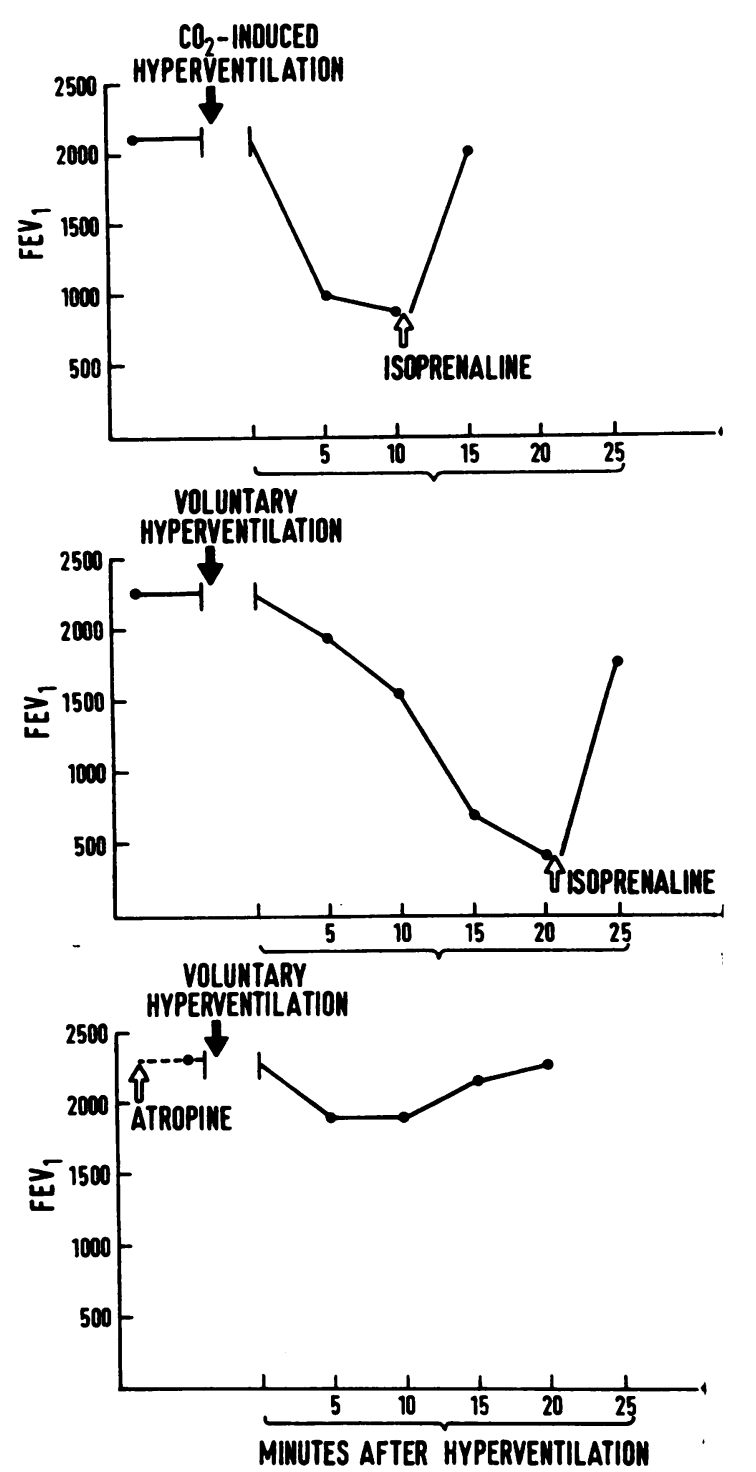

FIG. 2. The effect of hyperventilation on the F.E.V.1: (top) carbon dioxide-induced hyperventilation; (middle) voluntary hyperventilation; (bottom) subcutaneous atropine before voluntary hyperventilation.

expect atropine to block this process. If the hyperventilation due to exercise is responsible for the post-exercise increase in airways resistance, a fall in the F.E.V $\cdot_{1}$ should occur after hyperventilation is performed at rest. The patient studied, unlike those reported by McNeill et al. (1966), had a marked fall in the F.E.V. $\cdot_{1}$ after carbon dioxide- induced hyperventilation and also after voluntary hyperventilation performed at rest (Fig. 2).

It is possible that the bronchoconstriction following exercise and hyperventilation in this patient is due to different mechanisms than those in the patients described by Jones et al. (1962) and McNeill et al. (1966), but the time relationship of the F.E.V. ${ }_{1}$ fall to exercise is similar. The fact that a fall in F.E.V..$_{1}$ was observed after voluntary over-breathing and carbon dioxide-induced hyperventilation as well as after exercise, and that atropine almost completely prevented a fall in F.E.V..$_{1}$ after exercise and voluntary over-breathing, suggests that the post-exercise fall in F.E.V. in this case was caused by the hyperventilation associated with exercise.

The release of an unknown bronchoconstrictor substance from the muscles during exercise has been postulated as the cause of the post-exercise fall in F.E.V..$_{1}$ in some asthmatic subjects (McNeill et al., 1966). It must be pointed out that, as this patient was obese, a considerable amount of muscular activity must have taken place either when performing voluntary over-breathing at rest or in carbon dioxide-induced hyperventilation, and therefore the release of a bronchoconstrictor substance from muscles remains a possibility.

Since these studies were performed the patient has been kept almost symptom-free by treatment with oral atropine sulphate.

I am grateful to Dr. N. W. Horne for his advice, encouragement, and permission to publish this case under his care. It is a pleasure to thank Miss S. Merchant for help with the exercise studies, Mr. T. C. Dodds, of the Medical Photography Unit, for preparation of the figures, Miss J. Holywell for secretarial assistance, and Dr. A. C. Douglas for advice and criticism.

\section{REFERENCES}

Hafez, F. F., and Crompton, G. K. (19f8). The forced expiratory volume after hyperventilation in bronchitis and asthma. Brit. $J$. Dis. Chest, in press.

Jones, R. S., Buston, M. H., and Wharton, M. J. (1962). The effect of exercise on ventilatory function in the child with asthma. Ibid., 56, 78.

Wharton, M. J., and Buston, M. H. (1963). The place of physical exercise and bronchodilator drugs in the assessment of the asthmatic child. Arch. Dis. Childh., 38, 539.

McDermott, M. (1962). Acute respiratory effects of the inhalation of coal-dust particles. J. Physiol., 162, 53P.

McKerrow, C. B., McDermott, M., and Gilson, J. C. (1960). A spirometer for measuring the forced expiratory volume with a simple calibrating device. Lancet, 1, 149.

McNeill, R. S., Nairn, Jean R., Millar, J. S., and Ingram, C. G. (1966). Exercise-induced asthma. Quart. J.' Med., 35, 55.

Nadel, J. A., Salem, H., Tamplin, B., and Tokiwa, Y. (1965). Mechanism of bronchoconstriction during inhalation of sulfur dioxide. J. appl. Physiol., 20, 164.

Needham, C. D., Rogan, M. C., and McDonald, I. (1954). Normal standards for lung volumes, intrapulmonary gas-mixing and maximum breathing capacity. Thorax, 9, 313.

Widdicombe, J. G., Kent, D. C., and Nadel, J. A. (1962). Mechanism of bronchoconstriction during inhalation of dust. J. appl. Physiol., 17, 613. 